\title{
Credible Information Sharing in Supply Chains - A Behavioral Assessment of Review Strategies
}

\author{
Thomas Neumann \\ Otto-von-Guericke \\ University Magdeburg \\ t.neumann@ovgu.de
}

\author{
Stephan Schosser \\ Otto-von-Guericke \\ University Magdeburg \\ stephan.schosser@ovgu.de
}

\author{
Bodo Vogt \\ Otto-von-Guericke \\ University Magdeburg \\ bodo.vogt@ovgu.de
}

\author{
Guido Voigt \\ University of Hamburg \\ guido.voigt@uni- \\ hamburg.de
}

\begin{abstract}
In laboratory experiments, we compare the ability of trigger strategies with that of (relatively complex) review strategies to coordinate capacity decisions in supply chains when demand forecasts are based on private information. While trigger strategies punish apparently uncooperative behavior (misstated demand forecasts) immediately, review strategies only punish when apparently misstated information culminates over several periods. We contribute to the existing literature on capacity coordination in supply chains by showing that repeated game strategies lead to a significant degree of forecast misrepresentation, although they theoretically support the truth-telling equilibrium. However, forecast misrepresentation is more pronounced in review strategies. This behavioral effect is diametrically opposed to the theoretically predicted benefit of review strategies.
\end{abstract}

\section{Introduction}

Consider a buyer (female pronouns) who asks her long-term supplier (male pronouns) to build capacity for a newly developed, innovative product's component. Before and while developing the product, the buyer conducts market research to estimate the market potential of this product and gain further end-customer insights. The buyer therefore obtains demand forecasts that are not immediately available to the supplier, but are valuable for his capacity decisions. When facing a low demand forecast, the buyer can choose between two information sharing strategies: First, she may signal a high demand forecast to her supplier, thereby encouraging a high capacity investment. However, if her orders turn out to be low, she risks losing her supplier's trust in their future business interactions. Second, she may want to avoid the risk of losing her supplier's trust and therefore share the real demand forecast.
To foster honest information sharing, the supplier may setup an information technology system that ignores (punishes) apparently inflated demand forecasts. In our model context, the basic punishment strategy idea is to avoid forecast inflation through the supplier's threat to ignore future forecasts if the buyer's orders turn out to be low, although she reported a high demand forecast. Trigger strategies - that punish apparently misstated forecasts immediately - would entirely avoid efficiency losses if a forecast can be unambiguously identified as either honest, or a lie. However, random demand events outside the buyer's control, may render an initially truthfully shared forecast highly unlikely. In this case, trigger strategies result in ignored forecasts although the buyer reported honestly, thus implying an unnecessary loss in efficiency. Review strategies overcome this issue by observing a buyer's forecasting behavior over several periods and only punish after repeated anomalies. Review strategies dominate trigger strategies, because they are expected to introduce punishment phases less often [23]).

While the theoretical comparison of trigger and review strategies provides a clear-cut prediction for supply chains with rational and profit-maximizing actors, it is not clear if review strategies' efficiency gains can be sustained for real decision makers, who may act boundedly rational, or pursue objectives other than profit maximization. In this study, we conduct laboratory experiments to evaluate review strategies. Although we believe that research on repeated game strategies can benefit from other empirical approaches (e.g., interview studies), we see one central advantage in experiments: With experiments, the critical aspects of repeated game strategies can be controlled and therefore a highly internally valid comparison of review and trigger strategies is possible. It is difficult to evaluate repeated game strategies in the field, as it seems highly problematic for researchers to discern whether analytical forecasts (e.g., from an enterprise resource planning systems) are inflated due to good will (e.g., 
factoring in expert knowledge), or due to strategic considerations (e.g., encouraging high capacity investments).

We focus our study very specifically on buyers' information sharing behavior. Buyers deal with an automated (computerized) supplier who follows a repeated game strategy, i.e., a trigger strategy, or a review strategy. We design the repeated game strategies such that truth-telling is the profit maximizing strategy. With this design, we ensure that all of the proposed repeated game strategy's critical parameters are common knowledge (e.g., the signals that are assessed as non-reliable, the kind of punishment after a nonreliable assessment, etc.). Implementing an automated strategy separates us - to the best of our knowledge from existing experimental studies on lying: Several studies investigate the antecedents of lying, or the impact of punishment and reputation systems on information sharing in human-human interaction (see literature review). However, an analysis of whether subjects follow a certain equilibrium strategy induced by another automated player following a repeated game strategy is not part of this literature. This distinction is important, because in human-human interactions without common-knowledge pre-committed repeated game strategies, lying may occur because the information sharing party correctly perceives this as the payoff maximizing strategy. In our setup, however, we rule this motive out by ensuring that truth-telling is payoff maximizing. We can therefore focus precisely on the behavioral effects of direct punishments (trigger strategy) vs. delayed punishments (review strategies) on truth-telling and supply chain efficiency.

Our contribution to the supply chain literature on forecast sharing and coordination is twofold. First, we show that there is a substantial degree of lying, even in situations where truth-telling is the profit-maximizing strategy. We observe that our analyzed review strategies are less effective than theoretically predicted. Thus, the gap between explicitly defined repeated game strategies and unstructured repeated interaction is lower than normative analysis predicts. Second, we show that buyers confronted with a review strategy convey unreliable signals significantly more often than buyers confronted with a trigger strategy. The theoretically predicted effect of fewer punishment phases in review strategies is offset by the behavioral tendency to lie more frequently. Overall, we find no significant supply chain performance differences between the trigger strategy and the review strategy.

\footnotetext{
1 The sequential rationality concept predicts that there is no coordination in the last round of the game. Applying backward
}

\section{Literature Review}

In the remainder, we discuss theoretical and experimental work on information sharing in the supply chain management area, before reviewing experimental work that addresses information sharing conflicts in more general settings.

\subsection{Supply chain management}

A lack of information sharing may cause efficiency losses (see, among other, [6, 19, 23] and the references therein). However, since supply chain parties are legally independent, differing goals may hamper truthful information sharing and the trust of the information receiving party may be lost due to the parties' strategic interaction. Information sharing in supply chains attracts research on normative models and on behavioral studies.

The normative stream analyzes how coordination mechanisms, such as contractual agreements, or repeated game strategies, provide incentives to ensure truth-telling and trust between the supply chain parties. Corresponding work assumes that all parties are totally rational utility maximizers. Models of one-shot games, or finitely repeated games ${ }^{1}$, show that complex nonlinear signaling, or screening, schemes can boost supply chain efficiency compared to simple linear transfer schemes (wholesale price contracts). While the research on signaling and screening contracts culminated in an immense body of knowledge for all kinds of supply chain planning situations (see $[4,6]$ and citing articles), there is still little empirical evidence that these contract formats are widely applied in practice (see [23], p. 81, or [5], pp. 474). Signaling and screening contracts often only serve as a benchmark for simpler schemes. Moreover, simpler wholesale price contracts prove to be effective when coupled with repeated game strategies (e.g., trigger strategy, review strategy) in infinitely repeated games. In this case, cooperation can be sustained if the future is valued sufficiently high, i.e., the discount factor is sufficiently large [23, 25-27]. We contribute to the literature on information sharing in supply chains by comparing two repeated game strategies - a trigger strategy and a review strategy in controlled laboratory experiments with a specific focus on buyers' behavior.

The behavioral work on information sharing in supply chains challenges the normative prediction that shared information is nothing but cheap talk (see [7] for a comprehensive review on cheap talk experiments).

induction then indicates that the finitely repeated game collapses to the one-shot game [13]. 
Özer et al. [21, 22], Hyndman et al. [17], and EbrahimKhanjari et al. [9] study the performance of wholesale price contracts in combination with - theoretically ineffective - forecast information sharing in laboratory experiments. A general insight is that the theoretical analysis of strategic forecast inflation in wholesale price contracts overstates the observed efficiency losses, because human decision makers tend to trust information that they believe is truthfully shared. We contribute to this stream of research by analyzing the information sharing behavior in a situation where truthtelling is the expected profit maximizing strategy.

\subsection{Information sharing in laboratory experiments}

Two players usually interact in behavioral experiments on information sharing: One player communicates the private information, while the other player receives the signal. Experimental literature focuses on two aspects of the game, (1) the reaction of the signal receiver to non-reliable signals, and (2) the preconditions which influence the sender's signal. In this literature review, as in our experiment, we focus on the behavior of the signal sender (= buyer) (e.g., [3]).

In experimental studies, lying, i.e., senders reporting non-reliable signals, frequently occurs, because it maximizes the sender's payoff. For example, only $39 \%$ of all subjects are honest and if they do not interact with others, the observed signal is private information, which even the experimenter does not know [12]. As soon as the subjects interact with other subjects, the relative frequency of honesty increases to $56 \%$ [24], or $66 \%$ [16], suggesting that the degree of lie aversion [20] increases if another subject faces negative consequences due to non-reliable signals. The frequency of nonreliable signals also depends on how often these negative consequences occur: Subjects behave more honest when the negative impact that lying has on others increases [14]. In our experimental design, the signal receiving supplier is an automated agent. Lying, therefore, has no financial consequences for human subjects and, from a behavioral perspective, seems more likely to be observed. Our experimental design, therefore, tests repeated game strategies when it seems most beneficial to apply them.

The frequency of lying does not only depend on its impact on others, but also on individual benefits. As the frequency of non-reliable signals decreases, the lower the own benefit from such signals are [14]. Hence, one does not expect any non-reliable signals if the signal sender derives no monetary benefit from providing such signals. In addition, the frequency of non-reliable signals increases if the true signal is never revealed to the recipient [2]. In other words, lying increases if the buyer knows that the supplier will never discover whether the signal he received from the buyer was honest or not. In sum, a simple way to decrease nonreliable signals is to ensure that such signals have a negative effect.

A simple approach to reduce the benefit of nonreliable signals is to observe the behavior of subjects and to punish frequent non-reliable signals by means of a reputation mechanism. The effect of reputation mechanisms and punishment has been studied more generally in cooperative acts, in which the behavior of others is directly observable and can therefore be punished more than in unverifiable information sharing. Initially, cooperation is high, but decreases over time if it is repeated finitely (e.g., [1,28]). The punishment of uncooperative behavior primarily helps to sustain cooperation over time [10]. While uncooperative behavior can be clearly identified and punished exactly when such actions are observable, punishments are less effective when they are not observable. In other words, if players only see the outcome, but not the associated action, they do not punish as often [15]. For our experiments, this implies that buyers would not expect too much punishment if game strategies are not repeated, because behavior cannot unambiguously be identified as cooperative or not. Thus, our study contributes in this context by determining whether carefully structured strategies can overcome this behavioral tendency by providing automated punishment rules.

In sum, the existing literature clearly shows that punishment mechanisms foster cooperation. However, this effect is usually hampered when signals' reliability can only be assessed probabilistically. Repeated game strategies seem to be a good candidate to boost efficiency in such environments. Since signals in our setting cannot be unambiguously categorized as truthful or not, trigger strategies are theoretically less effective than review strategies. We contribute to the existing literature by comparing competing strategies in carefully devised laboratory experiments.

\section{Repeated game strategies}

One-shot game: We consider the supply chain setup as described in Ren et al. [23]. The supplier has to build up capacity, $K$, before the end-customer demand, $d$, is realized. The buyer orders the realized demand, $d$, from her supplier, which yields an end-customer price of $r$. The supplier charges a wholesale price, $w$, for every unit delivered to the buyer. The supplier's unit capacity cost is $c$. Table 1 summarizes the notation of the game. 
Table 1. Notation of the one-shot game

\begin{tabular}{|l|l|}
\hline$D_{i}, i \in\{h, l\} ; d$ & $\begin{array}{l}\text { Random end-customer demand; } \\
\text { demand realization from } D_{i}\end{array}$ \\
\hline $\begin{array}{l}F_{i}(\cdot) ; f_{i}(\cdot), i \\
\in\{h, l\}\end{array}$ & $\begin{array}{l}\text { Cumulative distribution function } \\
\text { (CDF); probability distribution } \\
\text { function (PDF) for } D_{i}\end{array}$ \\
\hline$\mu_{i} ; \sigma_{i}, i \in\{h, l\}$ & $\begin{array}{l}\text { Mean; standard deviation of } D_{i} \\
\text { with } \sigma_{h}=\sigma_{l}=\sigma\end{array}$ \\
\hline$p$ & $\begin{array}{l}\text { Probability of high market } \\
\text { demand }\end{array}$ \\
\hline$r$ & End-customer price \\
\hline$w$ & $\begin{array}{l}\text { Wholesale price (paid from buyer } \\
\text { to supplier) for each unit } \\
\text { delivered }\end{array}$ \\
\hline$c$ & Supplier's unit capacity cost \\
\hline$s \in\{h, l\}$ & $\begin{array}{l}\text { Customer's signal of demand } \\
\text { forecast }\end{array}$ \\
\hline$K_{a}, a \in(0, h, l)$ & $\begin{array}{l}\text { Capacity decision of supplier } \\
\text { under trust, } s=a, \text { and mistrust, } \\
a=0\end{array}$ \\
\hline$\pi^{S}(\cdot), \pi^{B}(\cdot)$ & $\begin{array}{l}\text { Expected profits supplier (S), } \\
\text { buyer (B) }\end{array}$ \\
\hline$\pi_{0}^{B}, \pi_{l, h}^{B}$ & $\begin{array}{l}\text { Buyer's ex-ante expected profits } \\
\text { under mistrust and trust } \\
\text { respectively }\end{array}$ \\
\hline
\end{tabular}

The end-customer demand, $D_{i}, i=\{h, l\}$, is random and follows either a distribution with a (relatively) low mean, $\mu_{l}$, or a relatively high mean, $\mu_{h}$. The standard deviation, $\sigma$, is identical for both demand distributions. The CDFs and PDFs are denoted by $F_{i}(\cdot)$ and $f_{i}(\cdot), i=$ $\{h, l\}$ respectively. The demand distribution that is relevant for a given period follows a Bernoulli process. The a priori probability of facing the end-customer demand distribution $D_{h}$ is $p$. The a priori probability of facing the end-customer demand $D_{l}$ is $1-p$. Information about the relevant demand distribution in a period is asymmetric. The buyer knows which one of the two distributions the end-customer demand follows in a given period, while her supplier only knows the a priori probabilities.

Forecast sharing: The buyer possesses more accurate forecast information than her supplier. The buyer knows the relevant period's demand distribution, while her supplier only knows the a priori probabilities of the demand distributions. The supplier is interested in a more accurate demand forecast, because this would enable him to better tailor the capacity to actual market conditions. The buyer can share her private demand forecast via a non-binding signal $s=\{h, l\}$. Her supplier may trust the signal and make his capacity decision, $K_{s}$, assuming that the demand follows $D_{s}$. Alternatively, the supplier may ignore the signal (further on denoted as

\footnotetext{
2 As with Ren et al. [23], we assume that all supply chain actors are fully rational and expected profit maximizers. This implicitly assumes that the payoffs of the other party do not matter (i.e., other regarding preferences are absent). However, considering interaction
}

punishment) and build up capacity $K_{0}$. Figure 1 summarizes the one-shot game's decision sequence.

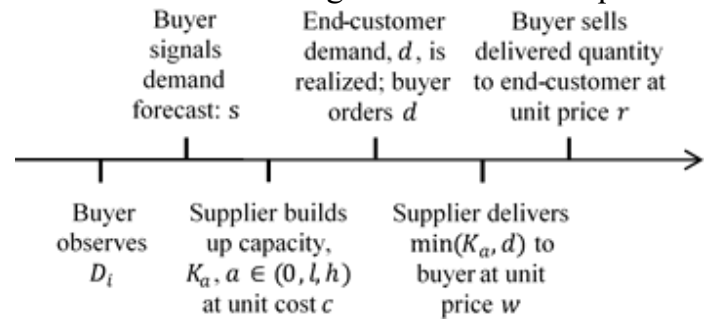

Figure 1. Decision sequence in the one-shot game

The buyer's and supplier's profits depend on the actual demand distribution, $D_{i}$, and the supplier's capacity decision $K_{a}, a \in(0, h, l){ }^{2}$

$$
\begin{aligned}
\pi^{S}\left(D_{i}, K_{a}\right)=w \cdot & \int_{0}^{K_{a}} d \cdot f_{i}(d) d d+w \\
& \cdot \int_{K_{a}}^{\infty} K_{\alpha} \cdot f_{i}(d) d d-K_{a} \cdot c \\
& =w \cdot \int_{0}^{K_{a}}\left(d-K_{a}\right) \cdot f_{i}(d) d d \\
& +(w-c) \cdot K_{a} \\
\pi^{B}\left(D_{i}, K_{a}\right)=(r- & w) \\
\cdot & \int_{0}^{K_{a}} d \cdot f_{i}(d) d d+(r-w) \\
& \cdot \int_{K_{a}}^{\infty} K_{a} \cdot f_{i}(d) d d \\
& =(r-w) \cdot \mu_{i}-(r-w) \\
& \cdot \int_{K_{a}}^{\infty}\left(d-K_{a}\right) f_{i}(d) d d
\end{aligned}
$$

We assume that a trusting supplier builds up the supply chain's optimal capacity. Thus, the supplier considers the supply chain's profit margin, $r-c$, instead of his individual profit margin, $w-c$ (see [23] p. 85). The supplier's optimal capacity decision under trust then follows from:

$$
\begin{array}{cc}
K_{S}=\underset{K}{\arg \max } & r \cdot \int_{0}^{K}(d-K) \cdot f_{S}(d) d d+(r-c) \\
& \cdot K \text { with } s \in(h, l) .
\end{array}
$$

The supplier may also mistrust the signal and make his capacity decision based on the a priori information:

$$
\begin{aligned}
K_{0}=\underset{K}{\operatorname{argmax}} p \cdot & \left(w \cdot \int_{0}^{K}(d-K) \cdot f_{h}(d) d d\right) \\
& +(1-p) \\
& \cdot\left(w \cdot \int_{0}^{K}(d-K) \cdot f_{l}(d) d d\right) \\
& +(w-c) \cdot K .
\end{aligned}
$$

Further, we denote the buyer's ex-ante expected profits (i.e., expected profits before the buyer

of supply chain actors (e.g., the buyer lies, the supplier suffers, and the buyer cares about this fact) might trigger various sorts of behavior (esp. related to other regarding preferences). As it stands now, we abstract from this issue. 
determined the actual demand distribution for the period) under mistrust

$$
\begin{aligned}
& \pi_{0}^{B}=p \pi^{B}\left(D_{h}, K_{0}\right)+(1-p) \pi^{B}\left(D_{l}, K_{0}\right) \\
& \quad \text { and under trust } \\
& \pi_{l, h}^{B}=p \pi^{B}\left(D_{h}, K_{h}\right)+(1-p) \pi^{B}\left(D_{l}, K_{l}\right)
\end{aligned}
$$

It has been well established that the buyer's dominant strategy in the one-shot game is to signal a high demand forecast, while the supplier's dominant strategy is to ignore the forecast. The supply chain parties are caught in a babbling equilibrium (see [23]). We briefly review the underlying line of argumentation.

Since the buyer does not carry any unit capacity costs, $c$, she has a strict preference for higher capacity levels. Because a trusting supplier builds up higher capacity under a high forecast than under a low forecast, $K_{h}>K_{l}$, the buyer's dominant strategy is to always signal a high demand forecast $s=h$. The supplier anticipates this uninformative signaling behavior and ignores/mistrusts the conveyed demand forecast.

Repeated interaction \& review strategy: Similar to Ren et al. [23], we model a long-lasting supplierbuyer relationship as an infinitely repeated game. The notation used for the analysis of the review strategy is summarized in Table 2. Let $t$ denote the time index of the stage game. The same decision sequence applies as in the one-stage game (see Figure 1). The discount rate is denoted by $\delta$. Time is divided into a sequence of review phases and punishment phases. The maximum length of a review phase is $R$ periods, the length of a punishment phase is $M$. During a review phase, the supplier evaluates by comparing the forecast with the order via statistical inference if the buyer's conveyed forecast is credible or not. If the reported forecast is assessed as credible, a credibility index $I_{t}$ is incremented by one. Low demand forecasts are always assessed as credible. When forecasts are high, the credibility index is only incremented if the determined demand is larger than a critical value, $d \geq d_{u}$. The credibility index is not incremented for demand realizations smaller than $d_{u}$, i.e., $I_{t}=I_{t-1}$. Thus, similar to truth-telling, the probability of being evaluated as credible is

$$
S=p\left[1-F_{h}\left(d_{u}\right)\right]+(1-p)
$$

The buyer fails the review at the end of a review phase if $I_{R}<q$, and passes the review if $I_{R} \geq q$, where $q$ denotes the credibility threshold. A review phase is restarted if the buyer no longer has an incentive to report truthfully, because her trust index is too high. We elaborate on the restart of a review phase later in this paper.

We denote the buyer's normalized expected profits at the beginning of the game as $\pi_{z}^{B}$, and the normalized expected profits when there are $n$ periods remaining in the review phase (i.e., in period $t=R-n$ ) and given a trust index $I_{t}=x$, as $\pi_{n, x}^{B}$.

Table 2. Notation of the repeated game and the review strategy

\begin{tabular}{|l|l|}
\hline$t$ & Time index of the stage game (period) \\
\hline$I_{t}$ & Credibility index in period t \\
\hline$q$ & Credibility threshold \\
\hline$d_{u}$ & $\begin{array}{l}\text { Demand realization threshold below which a } \\
\text { high demand forecast signal is assessed as } \\
\text { untruthful }\left(d<d_{u}\right)\end{array}$ \\
\hline$R$ & Length of the review phase \\
\hline$n$ & $\begin{array}{l}\text { Number of periods remaining in the review } \\
\text { phase }\end{array}$ \\
\hline$M$ & Length of the punishment phase \\
\hline$\delta$ & $\begin{array}{l}\text { Discount factor } \\
\text { when reporting honestly }\end{array}$ \\
\hline$\lambda$ & $\begin{array}{l}\text { Probability of failing the review despite } \\
\text { reporting honestly }\end{array}$ \\
\hline$t^{S}$ & $\begin{array}{l}\text { Earliest point at which a review phase is } \\
\text { restarted }\end{array}$ \\
\hline$\pi_{z}^{B}(\cdot)$ & $\begin{array}{l}\text { Buyer's normalized expected profits at the } \\
\text { beginning of a review phase }\end{array}$ \\
\hline$\pi_{n, x}^{B}$ & $\begin{array}{l}\text { Buyer's normalized expected profits when } \\
\text { there are } \mathrm{n} \text { periods remaining in the review } \\
\text { phase (i.e., in period } \mathrm{t}=\mathrm{R}-\mathrm{n}) \text { and given a } \\
\text { trust index } I_{t}=x .\end{array}$ \\
\hline
\end{tabular}

Truth-telling equilibrium: For our laboratory experiments, we construct the review strategy parameters in such a manner that truth-telling and trust form an equilibrium. The review strategy parameters must therefore ensure that a) in each period during the review phase, the buyer conveys the forecast truthfully, even if the trust index needs to be incremented in order to avoid failing the review, and b) that the buyer reports the forecast truthfully at the beginning of a new review phase.

We first formalize condition (a) - that is, the buyer's credibility index $I_{t}$ must be incremented in all periods $1 \leq n \leq R-1-$ in order to avoid failing the review. In any given period of the review phase, the buyer reports truthfully whether

$$
\begin{aligned}
(1-\delta) \pi^{B}\left(K_{h}, D_{l}\right) & +\delta\left(1-F_{l}\left(d_{u}\right)\right) \pi_{n-1, q-(n-1)}^{B} \\
& +F_{l}\left(d_{u}\right)\left[\delta\left(1-\delta^{M}\right) \pi_{0}^{B}\right. \\
& \left.+\delta^{M+1} \pi_{z}^{B}\right] \\
& \leq(1-\delta) \pi^{B}\left(K_{l}, D_{l}\right) \\
& +\delta\left(1-F_{h}\left(d_{u}\right)\right) \pi_{n-1, q-(n-1)}^{B} \\
& +F_{h}\left(d_{u}\right)\left[\delta\left(1-\delta^{M}\right) \pi_{0}^{B}\right. \\
& \left.+\delta^{M+1} \pi_{z}^{B}\right]
\end{aligned}
$$

The left-hand side of (8) formalizes the buyer's normalized expected profits when lying. The first term is the normalized expected profit when facing low demand and reporting high demand. The second term depicts the normalized expected profits when the lie is not revealed (i.e., the demand is higher than the threshold $d_{u}$ ), and the trust index is therefore 
incremented by one. The third term depicts the normalized expected profits when the lie is detected (i.e., the demand is lower than the threshold $d_{u}$ ). In this case, the buyer faces $M$ periods of mistrust. Afterwards, a new review phase starts with normalized expected profits of $\pi_{z}^{B}$. In turn, the right-hand side of (8) formalizes the normalized expected profits when the buyer reports truthfully. Because of the stochastic nature of a signal assessed as credible even under truthful reporting, all three basic terms on the left-hand side of the inequality also occur. Rearranging (8) gives

$$
\begin{aligned}
& \pi^{B}\left(K_{h}, D_{l}\right)-\pi^{B}\left(K_{l}, D_{l}\right) \\
& \leq \frac{F_{l}\left(d_{u}\right)-F_{h}\left(d_{u}\right)}{(1-\delta)}\left[\delta \pi_{n-1, q-(n-1)}^{B}\right. \\
& \left.-\left[\delta\left(1-\delta^{M}\right) \pi_{0}^{B}+\delta^{M+1} \pi_{z}^{B}\right]\right]
\end{aligned}
$$

We can replace (see [23] p. 89)

$$
\begin{aligned}
\pi_{n-1, q-(n-1)}^{B}=(1 & -\delta) \pi_{l, h}^{B} \sum_{i=0}^{n-2}(S \delta)^{i} \\
& +\pi_{z}^{B}(S \delta)^{n-1} \\
& +\left[\left(1-\delta^{M}\right) \pi_{0}^{B}\right. \\
& \left.+\delta^{M} \pi_{z}^{B}\right] \sum_{i=1}^{n-1}(1-S) \delta^{i} S^{i-1}
\end{aligned}
$$

in (9) and it follows

$$
\begin{aligned}
\pi^{B}\left(K_{h}, D_{l}\right)-\pi^{B}\left(K_{l}, D_{l}\right) & \\
\leq & \frac{\left(F_{l}\left(d_{u}\right)-F_{h}\left(d_{u}\right)\right)}{(1-\delta)} \delta \\
& \cdot\left[(1-\delta) \pi_{l, h}^{B} \sum_{i=0}^{n-2}(S \delta)^{i}\right. \\
& +\pi_{z}^{B}(S \delta)^{n-1} \\
& +\left[\left(1-\delta^{M}\right) \pi_{0}^{B}\right. \\
& \left.+\delta^{M} \pi_{z}^{B}\right]\left(\sum_{i=1}^{n-1}(1\right. \\
& \left.\left.-S) \delta^{i} S^{i-1}-1\right)\right]
\end{aligned}
$$

The buyer's normalized profits at the beginning of a review phase can be approximated by (see [23] p. 92)

$$
\begin{aligned}
\pi_{z}^{B}=\frac{\left(1-\delta^{R-q}\right) \pi_{l, h}^{B} \lambda}{1-\delta^{R-q+M} \lambda-\delta^{t_{s}}(1-\lambda)} \\
+\frac{\delta^{R-q}\left(1-\delta^{M}\right) \pi_{0}^{B} \lambda}{1-\delta^{R-q+M} \lambda-\delta^{t_{s}}(1-\lambda)} \\
+\frac{\left(1-\delta^{t_{s}}\right) \pi_{l, h}^{B}(1-\lambda)}{1-\delta^{R-q+M} \lambda-\delta^{t_{s}}(1-\lambda)}
\end{aligned}
$$

where $\lambda$ denotes the probability that the customer will fail the review despite reporting truthfully and $t_{s}$ denotes the earliest point at which the review phase can be restarted. Ren et al. [23] show that the likelihood of the buyer failing the review if she reports the forecast always truthfully and is only evaluated at date $R$, determines an upper bound for this probability. This

\footnotetext{
${ }^{3}$ Note that a punishment phase may not be triggered even if some of the reports are assessed as untruthful, as long as $R \neq q$. This is the theoretical advantage of review strategies, because punishment phases
}

probability follows a binomial distribution, i.e., we use the following upper bound

$$
\lambda=\left(\begin{array}{c}
R \\
R-q+1
\end{array}\right)(1-S)^{R-q+1} S^{q-1}
$$

A review phase is restarted if the buyer has no incentive to truthfully report a forecast, because her trust index is too high. Thus, we do not only have to check whether the buyer reports truthfully if the trust index has to be incremented in each period, i.e., $I_{n}=q-n$, but also whether one or more forecasts might still not be reliable, i.e., $I_{n}>q-n .{ }^{3}$ We now formulate condition (b) that must hold in a truth-telling equilibrium.

In the first period of a new review phase (where there is still leeway to be assessed as not reliable without failing the review), the buyer reports truthfully as long as the following inequality holds:

$$
\begin{aligned}
& \left(F_{l}\left(d_{u}\right)-F_{h}\left(d_{u}\right)\right) \\
& \cdot\left(\left(\pi_{l, h}^{B}-\pi_{z}^{B}\right)\right. \\
& \cdot\left[\sum_{i=0}^{q-2}\left(\begin{array}{c}
R-q+i \\
R-q
\end{array}\right) \delta^{R-q+i+1} S^{i}(1-S)^{R-q}\right. \\
& \left.-\sum_{i=0}^{R-q-1}\left(\begin{array}{c}
q-1+i \\
q-1
\end{array}\right) \delta^{q+1}(1-S)^{i} S^{q-1}\right] \\
& -\left(\begin{array}{c}
R-1 \\
R-q
\end{array}\right) S^{q-1}(1-S)^{R-q} \sum_{i=1}^{M} \delta^{R+i}\left(\pi_{z}^{B}\right. \\
& \left.\left.-\pi_{0}^{B}\right)\right) \geq \pi^{B}\left(K_{h}, D_{l}\right)-\pi^{B}\left(K_{l}, D_{l}\right)
\end{aligned}
$$

The left-hand side of Formula (14) depicts the benefit of reporting truthfully in a given period by mapping all possible payoff paths and the corresponding probabilities. As long as the inequality holds, the buyer has no incentive to report dishonestly in order to obtain the short-term gain depicted on the right-hand side of the inequality. We refer to Ren et al. [23] (p. 90) for further interpretation of this formula.

Finally, from (14), we can compute the earliest point at which a review phase is restarted, which we need in order to numerically evaluate the incentive compatibility in (a). The buyer has the least incentive to report truthfully if the trust index has been incremented in each period so far, i.e., if $I_{R-n}=R-n$. Thus, the earliest point at which the review phase may be restarted can be computed numerically by iteratively reducing $R$ and $q$ in formula (14) by one unit. Once the left-hand side of formula (14) turns negative, the earliest point $t_{s}$ is identified and can be replaced in (12). The obtained lower bound of $\pi_{z}^{B}$ can then be used to calculate incentive compatibility in formula (11).

Finally, note that we refer to a review strategy whenever the buyer might be evaluated as dishonest at

are expected to occur less frequently than in a trigger strategy, where $R=q$. 
least once (i.e., the credibility index is not incremented), while not entering the punishment phase, i.e., credibility index is smaller than the review length $(q<R)$. We refer to a trigger strategy whenever each negative assessment leads directly to punishments (i.e., $R=q$ ).

\section{Experiment}

The focus of our experiment is the buyer's reaction to a supplier's given repeated game strategy. We analyze the performance of two repeated game strategies - the review strategy and the trigger strategy - by varying the credibility threshold $q$ and the review length $R$ between treatments. We designed the repeated game strategies such that they support truth-telling. We automated the supplier's decision and thereby eliminate potential fairness concerns in the supply chain interaction. All parameters were known to the buyer, such that we expected a fully rational and profitmaximizing buyer to report truthfully throughout the game. In the following, we first present the game parameters that are identical in both treatments, thereafter we turn to our treatment design, and finally we present the details of our experimental procedure.

\subsection{Parameterization}

Customer demand is normally distributed with $D_{l} \sim \mathcal{N}\left(150,40^{2}\right)$ and $D_{h} \sim \mathcal{N}\left(300,40^{2}\right)$. The high demand distribution has an a priori probability of $p=$ 0.5 . We set the end-customer price to $r=12$, the wholesale price to $w=7$, and the unit capacity cost to $c=6$.

At the end of each period, a random draw decides, with probability 0.1 , whether the game ends, or another base game is played. We thus induce a discount factor of $\delta=0.9$. A high forecast signal $s=h$ is assessed as credible if $d \geq d_{u}=200$. A punishment phase of $M=$ 4 periods starts if the buyer cannot reach the credibility threshold $q$ in the remainder of the current review phase.

Table 3. Buyer payoff matrix

\section{Low demand $D$}

\begin{tabular}{|c|c|c|}
\hline & Review phase & $\begin{array}{c}\text { Punishment } \\
\text { phase }\end{array}$ \\
\hline$s=l$ & $\pi^{B}\left(D_{l}, K_{l}\right)=690.16$ & $\pi^{B}\left(D_{l}, K_{0}\right)$ \\
\hline$s=h$ & $\pi^{B}\left(D_{l}, K_{h}\right)=750.00$ & $=637.54$ \\
\hline \multicolumn{3}{|c|}{ High demand $D_{h}$} \\
\hline & Review phase & $\begin{array}{c}\text { Punishment } \\
\text { phase }\end{array}$ \\
\hline$s=l$ & $\pi^{B}\left(D_{h}, K_{l}\right)=749.40$ & \multirow{2}{*}{$\begin{array}{l}\pi^{B}\left(D_{h}, K_{0}\right) \\
=663.70\end{array}$} \\
\hline$s=h$ & $\pi^{B}\left(D_{h}, K_{h}\right)=1,380.30$ & \\
\hline
\end{tabular}

The payoff in each of the buyer's periods depends on the demand realization $d$, the current phase - i.e., the review phase or the punishment phase - and, in the review phase, on her signal $s$. The supplier's capacity decisions are $K_{0}=132.79, K_{l}=150, K_{h}=300$. The buyer's expected profits in the review phase and punishment phase are summarized in Table 3.

\subsection{Experimental procedure and design}

We recruited 48 subjects from a seminar on behavioral economics to participate in our experiments. We randomly assigned the subjects to one of two sessions (26 subjects to session 1 and 22 subjects to session 2). All subjects participated in two treatments: the review treatment and the trigger treatment. We thus focused on a with-in subject comparison. In session 1 (2), we started with the review (trigger) treatment, followed by the trigger (review) treatment. We randomized the number of periods per treatment and session before conducting the experiment (review treatment: 30 periods; trigger treatment: 25 periods) but did not inform the subjects how many rounds they would be playing. The subjects only knew the probabilities with which we simulated the number of rounds. In both treatments and sessions, we ensured that the relative frequency of high and low demands was equal within a review phase and within a punishment phase. By this means, we ensured that there were no highly unlikely realization sequences that could confound our results.

We played the review treatment with a review phase lasting for $R=10$ and a credibility threshold of $q=9$ to evaluate the effect of the review phase. The earliest point at which the review phase is restarted is $t_{S}=4$. The trigger treatment has a review phase of $R=1$ and a credibility threshold of $q=1$, i.e., the buyer must be assessed as credible in each period in order to avoid entering the punishment phase.

At the start of each session, we assigned each subject to a random seat in the laboratory. The subjects received written instructions (see online appendix at http://www.emwifo.ovgu.de/Research/Supplementary+ material.html) that captured the contents of the experiment that did not change between treatments. All the relevant game and treatment data were available on the computer screen. We answered all questions in private, before we played 20 training periods with $\delta=$ 0.0 , which we did not pay off. Thereafter, each subject played the two computerized treatments (z-Tree, [11]): the review treatment and the trigger treatment. Beside the parameters described in Section 4.1, the computer screen displayed the probability for every combination of low and high demand in the remaining periods of the current review/punishment phase, as well as the distribution of demands $d$ for both $D_{l}$ and $D_{h}$. After the two treatments, we paid the subjects according to their 
performance in the game. The subjects received $€ 0.25$ for 1,000 points. All in all, the subjects earned an average of $€ 13.62$ for an experiment lasting about two hours.

\section{Results}

In the remainder of this section, we present the experimental results. We focus our analysis on the first 20 periods, ensuring that every honest player who is not mistakenly identified as not reliable, played at least two complete review phases of 10 periods.

\subsection{Honesty}

According to Ren et al. [23], we designed the review strategy such that truth-telling and trust is the payoff maximizing strategy, i.e., we expect the subjects to report their true demand distribution throughout the game. Since the punishment cost for the subject is identical in both treatments, and the consequences of being assessed as non-reliable are more direct in the trigger treatment (i.e., assessed non-reliability immediately leads to a punishment phase), truth-telling and trust are also the equilibrium in this treatment. In sum, we expect truth-telling in both treatments throughout all periods.

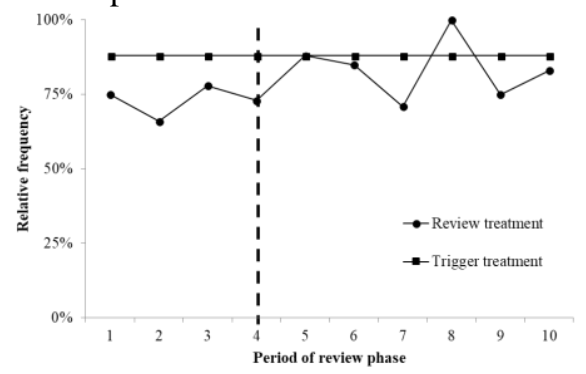

\section{Figure 2. Honesty per period of review phase} (given $d=l$ )

In the review treatment, nine subjects never lie, while 30 subjects never lie in the trigger treatment. In $88 \%$ (standard deviation [SD]: 0.26) of all occurrences of a low demand, the subjects in the trigger treatment are honest. In the review treatment, however, the subjects are only honest in 75\% (SD: 0.23) of the periods with low demand. Hence, the subjects are significantly more honest in the trigger treatment than in the review treatment (Wilcoxon test, two-sided, $\mathrm{p}=0.001$ ). Note that the high probability of lying in the review treatment is not solely based on behavior in the $4^{\text {th }}$ period $\left(t_{S}=4\right)$ of the review phase to ensure that the review phase lasts for 10 periods (see Figure 2, dashed vertical line): In 8 out of 10 periods in the review phase, the average honesty in the review treatment lies below the average honesty in the trigger treatment per period. In sum, we find - in contrast to game theoretic prediction - lying in both treatments, but a higher level in the review treatment.

\subsection{Punishments}

According to Ren et al. [23], we should expect fewer punishment phases in our review treatment than in the trigger treatment if all the subjects were to follow the truth-telling strategy. However, we observe more lying in the review treatment (see Section 5.1) than in the trigger treatment. This effect might diminish the theoretically positive consequences of not directly entering the punishment phase in the review treatment once a subject is assessed as not reliable.

Subjects in the review treatment enter the punishment phase an average 0.58 times (SD: 0.77), while they enter it 0.71 times (SD: 1.05) in the trigger treatment. Contrary to the theoretical prediction under a truth-telling strategy, the mean frequency of the punishment phases does not differ significantly between the treatments (Wilcoxon test, two-sided, $\mathrm{p}=0.475$ ).

As argued above, the lack of treatment differences might be due to a higher lying frequency in the review treatment. We therefore analyze the impact of lying on the frequency of punishment phases in a mixed effect logistic regression, using each decision (per period and subject) as one observation.

Table 4. Regression analysis of influencing factors on punishment in the next period Model I

\begin{tabular}{|c|c|c|c|c|}
\hline & \\
\hline \# of lies & -- & & 3.932 & $(0.34)^{* *}$ \\
\hline $\begin{array}{l}\text { Dummy } \\
\text { trigger }\end{array}$ & 0.197 & $(0.26)$ & 0.852 & $(0.29)^{* * *}$ \\
\hline Intercept & -3.634 & $(0.23)^{* *}$ & -5.472 & $(0.36)^{* *}$ \\
\hline $\mathrm{N}$ & 1920 & & 1920 & \\
\hline AIC & 562.6 & & 384.6 & \\
\hline $\mathrm{BIC}$ & 579.3 & & 406.9 & \\
\hline Log likel. & -278.3 & & -188.3 & \\
\hline $\begin{array}{l}\text { Notes: } \\
\text { coefficien } \\
\text { significan } \\
\text { criterion, }\end{array}$ & $\begin{array}{l}\text { ie signi } \\
\text { s are: } \\
\text { e levels } \\
\text { IC - Bay }\end{array}$ & nce le & $\begin{array}{l}\text { S of } t \\
\text { No } \mathrm{s} \\
- \text { Akaik } \\
\text { tion cri }\end{array}$ & $\begin{array}{l}\text { observ } \\
\text { indica } \\
\text { nformat } \\
\text { ion) }\end{array}$ \\
\hline
\end{tabular}

The variable "\# of lies" captures the number of not reliable signals the buyer reported to the supplier in previous periods of the treatment. For example, the former variable would be two for a buyer who reported reliably in eight out of the ten previous periods. The dummy trigger is one for our trigger treatment and captures the treatment differences. The results in Table 4 show that the likelihood of punishment phases increases with the number of lies and is significantly higher in our trigger treatment (column "Model II"). We further observe that this effect is non-significant if we 
omit to account for the number of lies (column "Model I"). Thus, the results clearly highlight that the positive effects of fewer punishment phases in the review treatment does not continue empirically, because buyers exhibit less reliable reporting behavior.

\subsection{Payoff consequences}

The subjects earned on average $1,003.50$ points per round $(S D: 87.81)$ in the review treatment compared to an average of 975.53 points per round $(S D: 108.15)$ in the trigger treatment. Although the average payoff in the review treatment is higher than in the trigger treatment, it does not differ significantly (Wilcoxon test, twosided, $p=0.111)$. Thus, the results are qualitatively, but not significantly in line with the theoretical prediction (i.e., subjects in the review treatment earn more than in the trigger treatment).

We ran two linear mixed regression models on the subjects' overall payoffs in the game to disentangle the influencing factors (see Table 5). In the first regression (the "Treatment effect" column), we evaluate the treatment with regard to the observed payoffs and find that the trigger treatment has a weakly significant negative effect. Taking the non-parametric analysis and the regression analysis into consideration, we find that the treatment effects on efficiency is almost significant.

Table 5. Regr. analysis for payoff differences to average payoff when always honest

\begin{tabular}{l|l|l|l|l} 
& \multicolumn{2}{|l|}{ Treatment Effect } & \multicolumn{2}{|c}{ Impact of honesty } \\
\hline \hline \# of lies & -- & & -22.43 & $(2.082)^{* *}$ \\
\hline $\begin{array}{l}\text { Dummy } \\
\text { Trigger }\end{array}$ & -27.97 & $(16.93)^{*}$ & -58.81 & $(13.62)^{* *}$ \\
\hline Intercept & -24.41 & $(14.22)^{*}$ & 43.34 & $(11.40)^{* *}$ \\
\hline \hline $\mathrm{N}$ & 96 & & 96 & \\
\hline AIC & 1155.5 & & 1083.4 & \\
\hline BIC & 1165.7 & & 1096.2 & \\
\hline Log likel. & -573.7 & & -536.7 &
\end{tabular}

Notes: The significance levels of the observed coefficients are: ${ }^{\star *} p<0.001$ and ${ }^{*} p<0.1$. No star indicates significance levels $p>0.1$. Log-likelihood statistic: 74.044 ( $p$-value: $<0.001$ )

Our second regression (the "Impact of honesty" column) adds the number of lies per subject to the former regression model. The trigger dummy now turns highly significant, indicating a clear efficiency gain in the review treatment relative to the trigger treatment. However, the higher frequency of lying in the review treatment compensates for part of this efficiency gain.

\section{Discussion}

We present two treatments that compare the review and trigger strategies in a supply chain experiment. Both strategies are designed such that they support the truthtelling equilibrium. However, we find a significant degree of lying under both strategies.

While we observe higher than theoretically predicted truthfulness and efficiency in cheap talk experiments (see [21, 22]), we observe that repeated game strategies' level of efficiency is worse than predicted. Our results thus indicate that the efficiency gap between cheap talk settings and repeated game strategies, which normative analysis predict, is overstated. An interesting avenue for future research is a direct comparison between cheap talk as an efficiency enhancer and repeated game strategies. Further, this result highlights that a company would suffer from allowing managers to communicate the forecast, instead of automatically transmitting them to their supply chain partners if they face an optimally designed repeated game strategy.

A comparison of two frequently discussed competing repeated game strategies shows that review strategies' higher complexity does not automatically lead to higher efficiency. As theoretically predicted, we do observe fewer punishment phases in the review strategy than in the trigger strategy if we fix the degree of lying. However, buyers exhibit a significantly higher tendency to lie when confronted with a review strategy, which diminishes the favorable effect of less punishment.

Our experiments are not designed to test the behavioral phenomena underlying this observation. We conjecture that review strategies' higher complexity makes it harder for subjects to identify truth-telling as the profit maximizing behavior. This is in line with experimental work (e.g., [8, 18]) showing that human participants find it difficult to apply backward-induction for more than two periods.

Another explanation for our observation that buyers lie more frequently in a review strategy than in a trigger strategy may be that the consequence of lying is harsher in the latter. Thus, increasing the burden of lying in the review strategy might improve the benefit of a theoretically better review strategy. Thus, further research should test whether our results are sensitive to parameter variations. However, once there is a practically relevant upper bound for critical parameters, such as the length of the punishment phase, or the discount factor, our results indicate that review strategies are not a better choice for all supply chain interactions.

\section{References}

[1] Andreoni, J., "Why free ride?", Journal of Public Economics, 37(3), 1988, pp. 291-304. 
[2] Boles, T.L., R.T. Croson, and J.K. Murnighan, "Deception and Retribution in Repeated Ultimatum Bargaining", Organizational Behavior and Human Decision Processes, 83(2), 2000, pp. 235-259.

[3] Brandts, J. and G. Charness, "Truth or Consequences: An Experiment", Management Science, 49(1), 2003, pp. 116130.

[4] Cachon, G.P. and M.A. Lariviere, "Contracting to Assure Supply: How to Share Demand Forecasts in a Supply Chain", Management Science, 47(5), 2001, pp. 629-646.

[5] Chiappori, P.-A. and B. Salanie, "Testing Contract Theory: A Survey of Some Recent Work", in Advances in Economics and Econometrics, M. Dewatripont, L.P. Hansen, and S.J. Turnovsky, Editors. 2003. Cambridge University Press.

[6] Corbett, C.J. and X. De Groote, "Supplier's optimal quantity discount policy under asymmetric information", Management Science, 46(3), 2000, pp. 444-450.

[7] Crawford, V., "A Survey of Experiments on Communication via Cheap Talk", Journal of Economic Theory, 78(2), 1998, pp. 286-298.

[8] Dufwenberg, M., R. Sundaram, and D.J. Butler, "Epiphany in the Game of 21", Journal of Economic Behavior \& Organization, 75(2), 2010, pp. 132-143.

[9] Ebrahim-Khanjari, N., W. Hopp, and S.M. Iravani, "Trust and Information Sharing in Supply Chains", Production and Operations Management, 21(3), 2012, pp. 444-464.

[10] Fehr, E. and S. Gächter, "Altruistic punishment in humans", Nature, 415(6868), 2002, pp. 137-140.

[11] Fischbacher, U., "z-Tree: Zurich toolbox for ready-made economic experiments", Experimental Economics, 10(2), 2007, pp. 171-178.

[12] Fischbacher, U. and F. Föllmi-Heusi, "Lies in Disguise An experimental study on cheating", Journal of the European Economic Association, 11(3), 2013, pp. 525-547.

[13] Fudenberg, D. and J. Tirole, "Perfect Bayesian equilibrium and sequential equilibrium", Journal of Economic Theory, 53(2), 1991, pp. 236-260.

[14] Gneezy, U., "Deception: The Role of Consequences", American Economic Review, 95(1), 2005, pp. 384-394.

[15] Grechenig, K., A. Nicklisch, and C. Thöni, "Punishment Despite Reasonable Doubt - A Public Goods Experiment with Sanctions Under Uncertainty", Journal of Empirical Legal Studies, 7(4), 2010, pp. 847-867.
[16] Hurkens, S. and N. Kartik, "Would I lie to you? On social preferences and lying aversion", Experimental Economics, 12(2), 2009, pp. 180-192.

[17] Hyndman, K., S. Kraiselburd, and N. Watson, "Aligning Capacity Decisions in Supply Chains When Demand Forecasts Are Private Information: Theory and Experiment", Manufacturing \& Service Operations Management, 15(1), 2013, pp. 102-117.

[18] Johnson, E.J., C.F. Camerer, S. Sen, and T. Rymon, "Detecting Failures of Backward Induction: Monitoring Information Search in Sequential Bargaining", Journal of Economic Theory, 104(1), 2002, pp. 16-47.

[19] Lee, H.L., V. Padmanabhan, and S. Whang, "Information Distortion in a Supply Chain: The Bullwhip Effect", Management Science, 43(4), 2004, pp. 1875-1886.

[20] López-Pérez, R. and E. Spiegelman, "Why do people tell the truth? Experimental evidence for pure lie aversion", Experimental Economics, 16(3), 2013, pp. 233-247.

[21] Özer, Ö., Y. Zheng, and K.-Y. Chen, "Trust in Forecast Information Sharing", Management Science, 57(6), 2011, pp. 1111-1137.

[22] Özer, Ö., Y. Zheng, and Y. Ren, "Trust, Trustworthiness, and Information Sharing in Supply Chains Bridging China and the United States", Management Science, 60(10), 2014, pp. 2435-2460.

[23] Ren, Z.J., M.A. Cohen, T.H. Ho, and C. Terwiesch, "Information sharing in a long-term supply chain relationship: the role of customer review strategy", Operations Research, 58(1), 2010, pp. 81-93.

[24] Sánchez-Pagés, S. and M. Vorsatz, "An experimental study of truth-telling in a sender-receiver game", Games and Economic Behavior, 61(1), 2007, 186-112.

[25] Sun, J. and L. Debo, "Sustaining long-term supply chain partnerships using price-only contracts", European Journal of Operational Research, 233(3), 2014, pp. 557-565.

[26] Taylor, T.A. and E.L. Plambeck, "Simple Relational Contracts to Motivate Capacity Investment: Price Only vs. Price and Quantity", Manufacturing \& Service Operations Management, 9(1), 2007, pp. 94-113.

[27] Taylor, T.A. and E.L. Plambeck, "Supply Chain Relationships and Contracts: The Impact of Repeated Interaction on Capacity Investment and Procurement", Management Science, 53(10), 2007, pp. 1577-1593.

[28] Weimann, J., "Individual behaviour in a free riding experiment", Journal of Public Economics, 54(2), 1994, pp. 185-200. 